\title{
Safety Climate in MT Mining: A Case Study
}

\author{
Ty Murphy $^{1} \cdot$ Hadi Aldossari $^{1} \cdot$ Lorri Birkenbuel $^{1} \cdot$ Scott Rosenthal $^{2} \cdot$ Daniel Autenrieth $^{1} \cdot$ Michael McGivern $^{1}$. \\ David Gilkey ${ }^{1}$
}

Received: 21 January 2021 / Accepted: 13 July 2021 / Published online: 13 August 2021

(c) Society for Mining, Metallurgy \& Exploration Inc. 2021

\begin{abstract}
A safety climate case study was carried out at a surface metal mine where investigators administered the Liberty Mutual Short Scale Safety Climate Survey to 365-368 miners to measure safety climate in consecutive years. Following the baseline safety climate survey in 2019, Foundations for Safety Leadership (FSL) training was conducted with 81 middle to upper management employees at the mine site. Investigators found statistically significant differences in the pre vs. posttraining FSL assessment scores of the middle to upper management employees who attended the training. The follow-up safety climate evaluation was compared to baseline scores and revealed no significant improvement. The overall baseline company safety climate score of 76.38 increased minimally to $76.50(p$-value $=0.616)$. Investigators also evaluated differences in safety climate between the company's three major divisions (operations, maintenance, and administration). Both years administration had the highest mean score and operations had the lowest mean score. The authors attributed the statistically significant differences found among the three major divisions to various dissimilarities in their work environments.
\end{abstract}

Keywords Safety climate $\cdot$ Safety culture $\cdot$ Mining

\section{Introduction}

Mining is an industry that presents an abundance of risk to its workers including physical, chemical, biological, and psychosocial hazards [1]. The mining industry has a long history of safety failures and resulting tragedies that have taken the lives of many miners. At the beginning of the twentieth century the average death toll per year reached greater than 1500 in the mining industry [2]. From 1911 through 1997, approximately 103,000 miners died in the United States due to safety failures [3]. Over the past 100 years fatality rates have plummeted from 329 per 100,000 in 1911 [3] 0 to 3.5 per 100,000 in 2017 [4]. In 2019, 15 miners died and 2431 recordable injuries were reported in the United States metal/ nonmetal mining industry [5]. Improvements in regulatory action, safety leadership, working conditions, and work

David Gilkey

dgilkey@mtech.edu

1 Department of Safety, Health and Industrial Hygiene, Montana Technological University, 1300 West Park St., Butte, MT 59701, USA

2 Department of Mining Engineering, Montana Technological University, 1300 West Park St., Butte, MT 59701, USA practices have been identified as key factors in reducing injury, illness, and fatality rates in mining $[3,6]$.

The first law to regulate mine safety was passed in 1891, followed by nine incremental pieces of legislation over the next 90 years that helped shape current mining safety standards and culminated in the creation of the Mine Safety Health Administration (MSHA) [7]. In 1977, the MSHA was created and continues operating today to develop and enforce safety and health regulations for all mines in the United States. The MSHA works strategically and cooperatively with industry, labor, and other federal and state agencies to reduce hazards and improve safety and health conditions for all the miners they oversee. By law, the MSHA must inspect and enforce safety and health regulations at all surface mine sites a minimum of two times annually. The MSHA also provides educational tools and other forms of assistance to mine operators with a goal of improving safety and health conditions for miners [7]. The MSHA initiated its Educational Field and Small Mine Services Program in 1999, with the intention of preventing mining accidents by assuring all miners receive effective training. The MSHA believes with certainty that there is a clear positive correlation between the level of quality training the miners receive and improving 
the safety and health of miners. This positive relationship has been demonstrated consistently in prior research [8].

Despite advancements, metal and nonmetal mining still presents substantial occupational safety and health hazards. Researchers analyzed 91 mining accidents and found the majority of the accidents were caused by inadequate safety leadership [9]. It has often been found that inadequate and/or deficient training by mine operators was responsible for the injury, fatality, or hazardous exposures $[6,10,11]$. Injuries have much greater economic impacts than just the direct costs. The direct to indirect cost ratio for an injury ranges between 1:3 and 1:5 [12]. Indirect costs include training costs for replacement workers, lost productivity, and increase error due to new employee learning curves, whereas direct costs include workers' compensation and medical expenses [13]. Prior research found that safety training both decreases days-away-from-work injuries and reduces overall injury rates [8].

\subsection{Safety Climate}

A crucial factor in reducing lost workdays and injury rates is a positive safety climate [14]. Safety climate was originally described in literature by Zohar as a summary of perceptions and assumptions that employees share about their work environment [15]. Another research team described safety climate as something that, "results from the enacted policies and procedures related to safety and the employee's perceptions and assumptions about the real priorities and consistency of management policies and procedures and their application for day-to-day business and decision making, particularly by frontline supervisors when company goals are conflicting" (p. 1045) [16].

Zohar found safety climate level could be measured and was associated with safety program effectiveness [15]. This association has led to an abundance of research aimed at developing tools to measure safety climate and identifying methods and strategies that are effective at improving safety climate. The Liberty Mutual Short-Scale Safety Climate Survey was validated by researchers using responses from 29,179 frontline workers from various industries including manufacturing, construction, and transportation [17]. One mining study of 235 workers found a positive relationship between miners' perceptions of safety climate, and their safety performance at a gold mining operation in Ghana [18]. Investigators also found that safety systems were good predictors of worker compliance and participation enhancing safety climate. In another study involving over 280 construction workers at 57 worksites, investigators found that high levels of hazard recognition were correlated with high levels of safety climate [19].

Safety climate has been linked to management communication and workers recognition [20] and other factors such as job satisfaction and turnover rate [21]. Safety communication and supervisory practices were positive predictors of compliance and safety participation [18]. Research from stone, sand, and gravel operations found that increasing safety climate perceptions leads to increased job satisfaction and a reduction in turnover intention [22]. Another investigator found turnover rates have negative implications in a variety of areas including safety and profits [23]. It has also been found that employees who were satisfied with their job were more likely to be safety compliant [24]. Their research was consistent with Zohar who reported over 200 research articles had been published on safety climate and the overwhelming conclusion among them was that high levels of safety climate were associated with lower injury, illness, and fatality rates [14].

Safety training has been shown to make an immediate and lasting improvement on safety climate. One study found that when health and safety training courses were provided to miners working at an Iranian mine, it made a significant change in their safety climate scores [25]. Safety climate surveys can be used to identify weaknesses in safety, which may reveal opportunities for improvement $[25,26]$. Other researchers found the largest difference among all factors influencing safety climate was the employee's perception of safety training [27]. Their research suggested that company owners/operators use training programs that have been designed and validated to increase safety climate. In Ghana, investigators looked at the relationship between safety climate elements and incident rates at four gold mine locations [26]. Investigators found the mines with lower incident rates consistently had higher safety climate scores than mines with higher incident rates [26]. Limited research has been conducted on safety climate in US mining and contributing factors such as leadership and training. There remains a gap in effective interventions for safety climate in mining and this research will add to that literature. The training intervention used in this study is relatively new and encouraging. This project will evaluate both training effectiveness and overall impact on safety climate.

\subsection{Foundations for Safety Leadership (FSL) Training}

The Foundations for Safety Leadership (FSL) was developed by the Center for Construction Research and Training (CPWR) and experts from the University of Colorado to improve safety in the high-risk industry. The FSL was designed specifically for construction and aimed at employees with supervisory responsibilities, with a goal of improving their safety leadership skills [28]. The program is opensource and has been downloaded over 100,000 times and allows for adaptation to various companies and industries [29]. Management leadership has been consistently shown 
in the literature to have a direct impact on company safety climate $[30,31]$. The FSL training program teaches five safety leadership skills that can be used to improve safety leadership practices, strengthen jobsite safety climate, and ultimately reduce the incidence of adverse safety and health outcomes [32]. The five key safety leadership skills are: (1) leads by example, (2) engages and empowers team members, (3) actively listens and practices three-way communication, (4) develops team members through teaching, coaching, and feedback, and (5) recognizes members for a job well done. Improving safety leadership skills in those with management responsibilities has been shown to improve jobsite safety climate and lead to fewer injuries, illnesses, and lost time incidents [33]. Positive safety leadership has been shown to have a significant negative correlation with turnover in the mining industry [34]. Investigators surveyed 255 miners in Ghana to evaluate safety management effects on turnover. They concluded that safety leadership is crucial in the management of occupational safety and health and employee turnover. Another research team found that many frontline leaders do not receive leadership training and therefore the FSL training program was designed to help provide a solution to this insufficiency [28].

\subsection{The Purpose of This Study}

Researchers partnered with a surface metal mining operation in Montana. The purpose of this study was to investigate and evaluate the company's safety climate by establishing a baseline measurement, followed by Foundations for Safety Leadership Training, and then a postintervention safety climate measurement to determine if the intervention was effective at improving the company's safety climate. The company requested that researchers investigate whether or not differences in safety climate existed between the company's major divisions (operations, maintenance, and administration). The intervention used in this study was the FSL training program, a 3-h workshop, conducted by a trained investigator with middle to upper management personnel at the mine. A FSL training program assessment was given immediately before and after training to determine if participants' knowledge of safety leadership skills improved and if they planned on utilizing the skills on their jobsite. The intervention was implemented after the baseline safety climate measurement in an effort to improve the company's safety climate as a whole. The null hypotheses used for the study were:

1. No statistically significant improvements would occur in the company's pre and posttraining safety climate measurements. HØ: Median Pre-Intervention $\geq$ Median Post-Intervention

2. No statistically significant differences existed between the three major divisions of the company in either year surveyed HØ: All company division's median safety climate scores are equal

3. No statistically significant improvements in the training assessment would occur in middle-upper management personnel's pre and posttraining FSL assessment scores. HØ: Median Pre-Training $\geq$ Median $_{\text {Post-Training }}$

Specific Aims were as follows:

1. Measure and evaluate overall companywide safety climate scores comparing pre to post intervention

2. Measure and evaluate potential differences in safety climate scores between the major divisions of the company

3. Measure and evaluate middle and upper management workers' knowledge of FSL skills pre to posttraining

\section{Methods}

This investigation was carried out in three phases: Phase (1) baseline safety climate survey in 2019; Phase (2) intervention using FSL training with pre and posttraining FSL assessment survey; and, Phase (3) follow-up safety climate survey one year later in 2020. Researchers secured authorization to use the Liberty Mutual, Safety Climate Short-Scale Survey from Liberty Mutual [35]. The same survey instrument was used for both pre and postintervention measurements. Company executives agreed to allow 365-368 fulltime employees at the mine to be surveyed both years. The 19-item survey instrument was designed to evaluate perceptions held by company personnel about management's commitment to safety and communication pertaining to safety [17]. All statistics in this paper were analyzed using Minitab® Statistical Software version 18, which included basic descriptive and frequencies to describe the population and mean scores.

Survey items were presented in the form of statements in two major categories, with statements $1-8$ pertaining to top management at the mine and statements 9-19 pertaining to the respondent's direct supervisor with Cronbach's alpha established at 0.94 and 0.97 , respectively [17]. For example, in relation to top management the following statements included, "tries to continually improve safety levels in each department" or "quickly corrects any safety hazard (even if it's costly)" [17]. Statements related to supervisors included the following examples: "frequently checks to see if we are all obeying the safety rules" and "discusses how to improve safety with us" [17]. Respondents were asked for their level of agreement with each statement using a $1-5$ scale where, $1=$ highly disagree to $5=$ highly agree [17]. The instrument was developed from the original 32-item safety climate survey that was validated by safety climate experts [36]. The survey was then shortened to 19 items in 
an attempt increase the utility of the survey for research and practice [17]. The short-scale survey has also been used in prior research and validated in various industries including manufacturing, construction, and transportation [17]. Additional questions were added to the safety climate survey to identify various demographic characteristics including the division the respondent worked in (operations, maintenance, or administration), gender, race, age, and time worked with the company. Mean scores within each division were generated. Differences and similarities between divisions' mean safety climate scores were analyzed using the Kruskal-Wallis test statistic with a $95 \%$ confidence interval. Comparing the individual safety climate statements and overall mean scores using two of the three divisions at a time was analyzed using the Mann-Whitney test statistic with a 95\% confidence interval.

All surveys in this study were administered and collected onsite during annual MSHA refresher training sessions in 2019 and 2020. Surveys were then collected by researchers for coding, data entry, and analysis. Differences and similarities between the pre and postintervention safety climate survey scores were analyzed using the Mann-Whitney test statistic with a $95 \%$ confidence interval. The investigation protocol was approved by the university's Institutional Review Board.

\subsection{FSL Training}

Two months after the baseline safety climate surveys were administered and scores were evaluated, the research team conducted a literature review to identify possible interventions. A summary of interventions that had demonstrated beneficial impacts on safety climate was provided to the company senior management. After senior management evaluated possible interventions and engaged the research team, the FSL was selected. In preparation for the FSL intervention, the lead team member contacted the CPWR for training. The CPWR representative directed the individual to a train the trainer experience with a competent FSL trainer. The researcher attended two full days of FSL training with the CPWR designated trainer. The researcher using CPWR tools administered the FSL training workshops with small groups over eight weeks. A total of 81 employees who had middle to upper management responsibilities at the mine were trained on FSL skills. Each session was accomplished using the 3-h workshop model designed by CPWR to teach the FSL's five critical leadership skills: (1) leads by example; (2) engages and empowers team members; (3) actively listens and practices 3-way communication; (4) develops team members through teaching, coaching, and feedback; and, (5) recognizes team members for a job well done [29]. Followup messaging was to the 81 supervisors at monthly intervals thereafter for five months to support FSL safety leadership skills implementation. Each month, one safety leadership skill was highlighted in a memo from senior management and encouraged among all workgroups.

Mining supervisors and company leaders who completed the 3-h FSL training workshop were given the FSL assessment survey pre and posttraining. This assessment was used to evaluate if the training was effective in improving safety leadership skills, and jobsite safety climate [32]. The pre- and posttraining assessments consisted of 23 statements associated with positive safety leadership skills. Respondents were asked to rate their level of agreement with each statement on a scale ranging from 1 to 5 where, $1=$ strongly disagree to $5=$ strongly agree. Pre and post-training assessments as a whole, and all 23 question individual questions on the pre and posttraining assessments were analyzed for potential differences using the Wilcoxon Signed-rank test with a $95 \%$ confidence interval.

\section{Results}

The study population demographics can be seen in Table 1 . The majority of respondents in combined surveys were male (96\%), Caucasian (96\%), and worked in operations (63\%). A total of 23 respondents (3.2\%) reported they had been employed with the company for over 30 years and 213 respondents (59\%) reported they had been working for the company less than 11 years. The age of participants ranged from less than 25 to over 65 years, with $49 \%$ of them younger than 45 years.

\subsection{9 and 2020 Safety Climate Scores}

The total company safety climate score in 2019 was 76.4 out of a possible 95. Researchers defined a positive response as either "agreeing" or "highly agreeing" with the statement. Slightly less than three-quarters (74.8\%) of total responses were positive for an overall mean score of 4.02/5.0, see Table 2. Three statements had less than $70 \%$ positive responses. Two of the three statements that had less than $70 \%$ positive responses were regard to top management. Three other statements saw greater than $80 \%$ positive responses. All three of the statements that had greater than $80 \%$ positive responses were with regard to top management, see Table 2. Less than two-thirds (64\%) of responses were positive with regard to the statement "Top management of this company considers safety when setting production speed and schedules" with an overall mean score of 3.77. More than four-fifths (83\%) of responses were positive with regard to the statement "Top management of this company gives safety personnel the power they need to do their job" with an overall mean 
Table 1 Study population demographics and work characteristics

\begin{tabular}{|c|c|c|c|c|c|}
\hline Variable & Characteristics & $\begin{array}{l}\text { Frequency }(n) \\
(2019)\end{array}$ & Percent (2019) & $\begin{array}{l}\text { Frequency }(n) \\
(2020)\end{array}$ & Percent (2020) \\
\hline \multirow[t]{3}{*}{ Division } & Operation & 178 & $61.2 \%$ & 156 & $67.2 \%$ \\
\hline & Maintenance & 93 & $32.0 \%$ & 61 & $26.3 \%$ \\
\hline & Administration & 20 & $6.9 \%$ & 15 & $6.5 \%$ \\
\hline \multirow[t]{2}{*}{ Gender } & Male & 263 & $96.0 \%$ & 292 & $96.0 \%$ \\
\hline & Female & 11 & $4.0 \%$ & 12 & $3.9 \%$ \\
\hline \multirow[t]{8}{*}{ Race } & Asian & 0 & $0.0 \%$ & 0 & $0.0 \%$ \\
\hline & Black & 0 & $0.0 \%$ & 1 & $0.0 \%$ \\
\hline & Caucasian & 308 & $92.8 \%$ & 335 & $94.9 \%$ \\
\hline & Latino & 3 & $0.9 \%$ & 3 & $0.9 \%$ \\
\hline & Pacific Islander & 1 & $0.3 \%$ & 1 & $0.3 \%$ \\
\hline & Native American & 5 & $1.5 \%$ & 3 & $0.9 \%$ \\
\hline & Mixed Race & 14 & $4.2 \%$ & 9 & $2.6 \%$ \\
\hline & Other & 1 & $0.3 \%$ & 1 & $0.3 \%$ \\
\hline \multirow{6}{*}{$\begin{array}{l}\text { Age } \\
\text { (y) }\end{array}$} & $18-25$ & 14 & $4.1 \%$ & 11 & $3.1 \%$ \\
\hline & 26- 35 & 90 & $26.4 \%$ & 93 & $26.1 \%$ \\
\hline & $36-45$ & 66 & $19.4 \%$ & 76 & $21.3 \%$ \\
\hline & $46-55$ & 107 & $31.4 \%$ & 106 & $29.7 \%$ \\
\hline & $56-65$ & 59 & $17.3 \%$ & 62 & $17.4 \%$ \\
\hline & More than 65 & 5 & $1.5 \%$ & 8 & $2.2 \%$ \\
\hline \multirow{10}{*}{$\begin{array}{l}\text { Time worked } \\
\text { (y) }\end{array}$} & Less than 5 & 102 & $29.8 \%$ & 114 & $32.0 \%$ \\
\hline & $5-10$ & 99 & $28.9 \%$ & 99 & $27.8 \%$ \\
\hline & $11-15$ & 55 & $16.1 \%$ & 37 & $10.4 \%$ \\
\hline & $16-20$ & 54 & $15.8 \%$ & 72 & $20.2 \%$ \\
\hline & $21-25$ & 7 & $2.0 \%$ & 10 & $2.8 \%$ \\
\hline & $26-30$ & 17 & $5.0 \%$ & 9 & $2.5 \%$ \\
\hline & $31-35$ & 8 & $2.3 \%$ & 11 & $3.1 \%$ \\
\hline & $36-40$ & 0 & $0.0 \%$ & 4 & $1.1 \%$ \\
\hline & $41-45$ & 0 & $0.0 \%$ & 0 & $0.0 \%$ \\
\hline & More than 45 & 0 & $0.0 \%$ & 0 & $0.0 \%$ \\
\hline
\end{tabular}

score of 4.26. Table 2 provides detailed safety climate scores for overall company year to year and by divisions.

The total company safety climate score for 2020 was 76.5 out of a possible 95 points. Over three-quarters (76.5\%) of all responses were positive for an overall mean score of 4.03/5.0. Two statements had less than $70 \%$ positive responses. One of the two statements that had less than $70 \%$ positive responses was with regard to top management. Four additional statements had a greater than $80 \%$ positive response rate. Three of the four statements that had greater than $80 \%$ positive response rate were with regard to top management. A little more than two-thirds $(68 \%)$ of all responses were positive with regard to the statement "top management listens carefully to workers' ideas about improving safety" for an overall mean score of 3.77. Eighty-five percent of responses were positive with the regard to the statement "top management gives safety personnel the power they need to do their job" for an overall mean score of 4.21 .
Looking at the division level, administration had the highest overall mean scores with a total of 83.1 from a possible 95 in 2019 and 83.3 in 2020, see Table 3. Minimal changes in safety climate scores were seen with none being significant. Slight decreases in means score were seen in 6 of 19 items and increases were seen in 9 of 19 items.

Maintenance had the next highest overall scores safety climate scores with a total of 77.9 in 2019 and 77.5 in 2020., please see Table 4 . One item was nearly significant a 0.06 regarding the statement, uses any available information to improve existing safety rules. This time decreased from 4.2 in 2019 to 4.0 in 2020 . Overall 7 of 9 items decreased minimally and 5 of 19 items increase slightly, no changes were significant at the 0.05 level.

Operations had the lowest overall mean scores in both 2019 and 2020 with totals of 75.2 and 76.5, respectively, for a $10 \%$ overall increase. We did see significant changes in two variables, see Table 5. The first statement pertained to topic management and their response to correcting safety hazards, 
Table 2 Comparison of safety climate scores for the company from 2019 to 2020

\begin{tabular}{|c|c|c|c|}
\hline Question/Variable & 2019 Mean (SD) & 2020 Mean (SD) & $\begin{array}{l}\text { Difference } \\
\text { in Means } \\
(p \text {-Value) }\end{array}$ \\
\hline 1. Tries to continually improve safety levels in each department & $4.2(0.87)$ & $4.2(0.82)$ & 0.85 \\
\hline 2. Quickly corrects any safety hazard (even if it's costly) & $3.9(0.10)$ & $3.9(0.89)$ & 0.72 \\
\hline 3. Requires each manager to help improve safety in his/her department & $4.1(0.89)$ & $4.0(0.84)$ & 0.16 \\
\hline 4. Uses any available information to improve existing safety rules & $4.2(0.80)$ & $4.1(0.79)$ & 0.06 \\
\hline 5. Listens carefully to workers' ideas about improving safety & $3.9(1.05)$ & $3.8(0.98)$ & 0.22 \\
\hline 6. Considers safety when setting production speed and schedules & $3.8(1.11)$ & $3.9(0.95)$ & 0.17 \\
\hline 7. Provides workers with a lot of information on safety issues & $4.1(0.90)$ & $4.1(0.83)$ & 0.25 \\
\hline 8. Gives safety personnel the power they need to do their job & $4.3(0.86)$ & $4.2(0.81)$ & 0.38 \\
\hline 9. Frequently checks to see if we are all obeying the safety rules & $3.9(1.07)$ & $4.0(0.93)$ & 0.34 \\
\hline 10. Discusses how to improve safety with us & $4.1(0.96)$ & $4.1(0.91)$ & 0.27 \\
\hline 11. Uses explanations (not just compliance) to get us to act safely & $4.0(0.98)$ & $4.0(0.88)$ & 0.60 \\
\hline 12. Emphasizes safety procedures when we are working under pressure & $4.0(0.98)$ & $4.0(0.90)$ & 0.53 \\
\hline 13. Frequently tells us about the hazards in our work & $4.0(1.01)$ & $4.0(0.94)$ & 0.81 \\
\hline 14. Reminds workers who need reminders to work safely & $3.9(1.11)$ & $4.0(0.97)$ & 0.48 \\
\hline 15. Makes sure we follow all the safety rules (not just the most important ones) & $4.1(0.99)$ & $4.1(0.83)$ & 0.53 \\
\hline 16. Insists that we obey safety rules when fixing equipment or machines & $4.2(0.91)$ & $4.1(0.89)$ & 0.55 \\
\hline 17. Is strict about safety at the end of the shift, when we want to go home & $4.0(1.02)$ & $4.0(0.87)$ & 0.66 \\
\hline 18. Spends time helping us to see problems before they arise & $3.8(1.12)$ & $3.9(0.98)$ & 0.65 \\
\hline 19. Frequently talks about safety issues throughout the work week & $4.1(1.02)$ & $4.0(0.97)$ & 0.140 \\
\hline
\end{tabular}

even if it was costly. The mean score was 3.7 in 2019 with a $10 \%$ increase in 2020 to 3.9 . The second significant variable pertained to supervisor frequently checking to see if employees were are all obeying the safety rules. In 2019, the mean scores for this statement was 3.8 with a $10 \%$ increase to 4.0 in 2020, see Table 5. Increases were seen in 10 of the 19 variables. Another statement pertaining to the supervisor, reminds workers who need reminders to work safely, was nearly significant with a $p$-value 0.08 . The 2019 mean score was 3.8 and increased to 4.0 in 2020.

\subsection{Comparing Safety Climate Score Between 2019 and 2020}

Figure 1 shows interval plots comparing all the overall company mean score and the three divisions' mean scores in 2019 and 2020 with $95 \%$ confidence intervals. The overall company's mean score increased from 4.02 in 2019 to 4.03 in 2020. The company's mean score increased on 10 out of the 19 statements in the survey. The Mann-Whitney statistical test found no statistically significant changes ( $p$-value $=0.616$ ) from 2019 to 2020 in the company's overall mean score. Nine of 19 statements from the 2019 survey had a mean score greater than 4.0 , while 11 of 19 statements on the 2020 survey registered a mean score greater than 4.0.

Administration had the highest score mean score (4.39), followed by maintenance (4.09), and then operations (3.96).
These mean scores showed statistically significant differences ( $p$-value $=0.007)$. Comparing administration to operations found statistically significant differences on 10 of the 19 statements. Comparing maintenance to operations found statistically significant differences on five of the 19 statements. Administration had a higher mean score than maintenance and operations on 18 of the 19 statements in the 2019 survey.

Figure 1 is an interval plot comparing the overall company climate score and all three divisions' mean scores in 2019 to 2020 with a $95 \%$ confidence interval.

Administration had the highest score mean score (4.40), followed by maintenance (4.08), and then operations (3.98). These scores showed statistically significant differences when comparing each division $(p$-value $=0.041)$. When comparing administration to operations we found statistically significant differences on 8 of the 19 statements. When comparing maintenance to operations we did not find statistically significant differences on any of the 19 statements. Administration had a higher mean score than maintenance and operations on all 19 statements in the 2020 survey.

\subsection{FSL Training}

The FSL training sessions were conducted one to two months after the 2019 safety climate survey. A total of eight training sessions were completed with 81 employees 
Table 3 Comparing safety climate scores for administration from 2019 to 2020

\begin{tabular}{|c|c|c|c|}
\hline Question/Variable & $\begin{array}{l}2019 \\
\text { Mean (SD) }\end{array}$ & $\begin{array}{l}2020 \\
\text { Mean (SD) }\end{array}$ & Difference between Means ( $p$-Value) \\
\hline $\begin{array}{l}\text { 1. Tries to continually improve } \\
\text { safety levels in each depart- } \\
\text { ment }\end{array}$ & $4.6(0.50)$ & $4.6(0.63)$ & 0.83 \\
\hline $\begin{array}{l}\text { 2. Quickly corrects any safety } \\
\text { hazard (even if it's costly) }\end{array}$ & $4.5(0.69)$ & $4.1(0.64)$ & 0.09 \\
\hline $\begin{array}{l}\text { 3. Requires each manager to } \\
\text { help improve safety in his/her } \\
\text { department }\end{array}$ & $4.7(0.47)$ & $4.2(0.86)$ & 0.07 \\
\hline $\begin{array}{l}\text { 4. Uses any available informa- } \\
\text { tion to improve existing safety } \\
\text { rules }\end{array}$ & $4.6(0.67)$ & $4.1(0.64)$ & 0.05 \\
\hline $\begin{array}{l}\text { 5. Listens carefully to workers' } \\
\text { ideas about improving safety }\end{array}$ & $4.3(0.80)$ & $3.9(0.80)$ & 0.18 \\
\hline $\begin{array}{l}\text { 6. Considers safety when setting } \\
\text { production speed and schedules }\end{array}$ & $4.3(0.87)$ & $4.1(0.61)$ & 0.22 \\
\hline $\begin{array}{l}\text { 7. Provides workers with a lot of } \\
\text { information on safety issues }\end{array}$ & $4.5(0.83)$ & $4.4(0.74)$ & 0.72 \\
\hline $\begin{array}{l}\text { 8. Gives safety personnel the } \\
\text { power they need to do their job }\end{array}$ & $4.7(0.66)$ & $4.8(0.56)$ & 0.63 \\
\hline $\begin{array}{l}\text { 9. Frequently checks to see if we } \\
\text { are all obeying the safety rules }\end{array}$ & $4.3(0.81)$ & $4.4(0.76)$ & 0.56 \\
\hline $\begin{array}{l}\text { 10. Discusses how to improve } \\
\text { safety with us }\end{array}$ & $4.3(0.89)$ & $4.6(0.65)$ & 0.45 \\
\hline $\begin{array}{l}\text { 11. Uses explanations (not just } \\
\text { compliance) to get us to act } \\
\text { safely }\end{array}$ & $4.5(0.77)$ & $4.2(0.70)$ & 0.24 \\
\hline $\begin{array}{l}\text { 12. Emphasizes safety proce- } \\
\text { dures when we are working } \\
\text { under pressure }\end{array}$ & $4.3(1.00)$ & $4.6(0.63)$ & 0.30 \\
\hline $\begin{array}{l}\text { 13. Frequently tells us about the } \\
\text { hazards in our work }\end{array}$ & $4.0(0.94)$ & $4.4(0.63)$ & 0.31 \\
\hline $\begin{array}{l}\text { 14. Reminds workers who need } \\
\text { reminders to work safely }\end{array}$ & $4.2(1.12)$ & $4.5(0.65)$ & 0.51 \\
\hline $\begin{array}{l}\text { 15. Makes sure we follow all the } \\
\text { safety rules (not just the most } \\
\text { important ones) }\end{array}$ & $4.4(0.83)$ & $4.6(0.50)$ & 0.45 \\
\hline $\begin{array}{l}\text { 16. Insists that we obey safety } \\
\text { rules when fixing equipment or } \\
\text { machines }\end{array}$ & $4.5(0.77)$ & $4.5(0.65)$ & 0.93 \\
\hline $\begin{array}{l}\text { 17. Is strict about safety at the } \\
\text { end of the shift, when we want } \\
\text { to go home }\end{array}$ & $4.1(1.15)$ & $4.4(0.66)$ & 0.53 \\
\hline $\begin{array}{l}\text { 18. Spends time helping us to see } \\
\text { problems before they arise }\end{array}$ & $4.1(0.88)$ & $4.1(0.86)$ & 0.92 \\
\hline $\begin{array}{l}\text { 19. Frequently talks about safety } \\
\text { issues throughout the work } \\
\text { week }\end{array}$ & $4.4(0.76)$ & $4.6(0.65)$ & 0.46 \\
\hline
\end{tabular}

who had middle to upper management responsibilities over an eight week period. Table 6 presents the pre and posttraining results of those employees who completed the FSL Training. The posttraining median score revealed statistically significant improvement compared to the pretraining median score. All 23 questions had statistically significant median score improvements when comparing pre and posttraining results. The pre-training assessment found nearly $90 \%$ (88.9\%) of employee responses were positive. In the posttraining assessment this number increased to just over $98 \%$ (98.1\%) of employee responses being positive. 
Table 4 Comparing safety climate scores for maintenance from 2019 to 2020

\begin{tabular}{|c|c|c|c|}
\hline Question/Variable & 2019 Mean (SD) & 2020 Mean (SD) & $\begin{array}{l}\text { Difference } \\
\text { between Means } \\
(p \text {-Value) }\end{array}$ \\
\hline 1. Tries to continually improve safety levels in each department & $4.2(0.86)$ & $4.0(0.89)$ & 0.13 \\
\hline 2. Quickly corrects any safety hazard (even if it's costly) & $4.1(0.87)$ & $4.0(0.88)$ & 0.64 \\
\hline 3. Requires each manager to help improve safety in his/her department & $4.2(0.95)$ & $4.1(0.79)$ & 0.34 \\
\hline 4. Uses any available information to improve existing safety rules & $4.2(0.84)$ & $4.0(0.77)$ & 0.06 \\
\hline 5. Listens carefully to workers' ideas about improving safety & $4.0(0.97)$ & $3.9(0.95)$ & 0.17 \\
\hline 6. Considers safety when setting production speed and schedules & $3.7(1.16)$ & $3.9(1.03)$ & 0.39 \\
\hline 7. Provides workers with a lot of information on safety issues & $4.1(0.97)$ & $4.1(0.73)$ & 0.81 \\
\hline 8. Gives safety personnel the power they need to do their job & $4.3(0.89)$ & $4.3(0.69)$ & 0.69 \\
\hline 9. Frequently checks to see if we are all obeying the safety rules & $4.1(1.04)$ & $4.2(0.77)$ & 0.74 \\
\hline 10. Discusses how to improve safety with us & $4.2(1.01)$ & $4.1(0.89)$ & 0.31 \\
\hline 11. Uses explanations (not just compliance) to get us to act safely & $4.0(1.04)$ & $4.0(0.84)$ & 0.73 \\
\hline 12. Emphasizes safety procedures when we are working under pressure & $4.0(1.09)$ & $4.1(0.79)$ & 0.84 \\
\hline 13. Frequently tells us about the hazards in our work & $4.1(1.06)$ & $4.1(0.95)$ & 0.86 \\
\hline 14. Reminds workers who need reminders to work safely & $4.1(1.02)$ & $4.2(0.90)$ & 0.90 \\
\hline 15. Makes sure we follow all the safety rules (not just the most important ones) & $4.2(0.96)$ & $4.2(0.73)$ & 0.34 \\
\hline 16. Insists that we obey safety rules when fixing equipment or machines & $4.3(0.97)$ & $4.3(0.79)$ & 0.43 \\
\hline 17. Is strict about safety at the end of the shift, when we want to go home & $4.0(1.06)$ & $4.1(0.78)$ & 0.96 \\
\hline 18. Spends time helping us to see problems before they arise & $4.0(1.16)$ & $4.0(0.93)$ & 0.51 \\
\hline 19. Frequently talks about safety issues throughout the work week & $4.1(1.06)$ & $4.0(1.01)$ & 0.47 \\
\hline
\end{tabular}

Table 5 Comparing safety climate scores for operations from 2019 to 2020

\begin{tabular}{|c|c|c|c|}
\hline Question/Variable & $\begin{array}{l}2019 \\
\text { Mean (SD) }\end{array}$ & 2020 Mean (SD) & $\begin{array}{l}\text { Difference } \\
\text { between } \\
\text { Means } \\
\text { ( } p \text {-Value) }\end{array}$ \\
\hline 1. Tries to continually improve safety levels in each department & $4.1(0.87)$ & $4.2(0.82)$ & 0.31 \\
\hline 2. Quickly corrects any safety hazard (even if it's costly) & $3.7(1.01)$ & $3.9(0.89)$ & $<0.01$ \\
\hline 3. Requires each manager to help improve safety in his/her department & $4.0(0.89)$ & $4.0(0.85)$ & 0.84 \\
\hline 4. Uses any available information to improve existing safety rules & $4.1(0.77)$ & $4.1(0.79)$ & 0.50 \\
\hline 5. Listens carefully to workers' ideas about improving safety & $3.7(1.06)$ & $3.8(0.98)$ & 0.60 \\
\hline 6. Considers safety when setting production speed and schedules & $3.8(1.07)$ & $3.9(0.95)$ & 0.25 \\
\hline 7. Provides workers with a lot of information on safety issues & $4.1(0.89)$ & $4.1(0.83)$ & 0.64 \\
\hline 8. Gives safety personnel the power they need to do their job & $4.2(0.84)$ & $4.2(0.82)$ & 0.73 \\
\hline 9. Frequently checks to see if we are all obeying the safety rules & $3.8(1.06)$ & $4.0(0.93)$ & $<0.01$ \\
\hline 10. Discusses how to improve safety with us & $4.1(0.89)$ & $4.1(0.91)$ & 0.64 \\
\hline 11. Uses explanations (not just compliance) to get us to act safely & $4.0(0.96)$ & $4.0(0.88)$ & 0.89 \\
\hline 12. Emphasizes safety procedures when we are working under pressure & $3.9(0.90)$ & $4.0(0.90)$ & 0.14 \\
\hline 13. Frequently tells us about the hazards in our work & $4.0(0.94)$ & $4.00 .95)$ & 0.76 \\
\hline 14. Reminds workers who need reminders to work safely & $3.8(1.11)$ & $4.0(0.97)$ & 0.08 \\
\hline 15. Makes sure we follow all the safety rules (not just the most important ones) & $4.0(1.00)$ & $4.1(0.83)$ & 0.53 \\
\hline 16. Insists that we obey safety rules when fixing equipment or machines & $4.1(0.91)$ & $4.1(0.89)$ & 0.45 \\
\hline 17. Is strict about safety at the end of the shift, when we want to go home & $3.9(0.96)$ & $4.0(0.87)$ & 0.60 \\
\hline 18. Spends time helping us to see problems before they arise & $3.8(1.07)$ & $3.9(0.98)$ & 0.55 \\
\hline 19. Frequently talks about safety issues throughout the work week & $4.1(0.98)$ & $4.0(0.97)$ & 0.25 \\
\hline
\end{tabular}




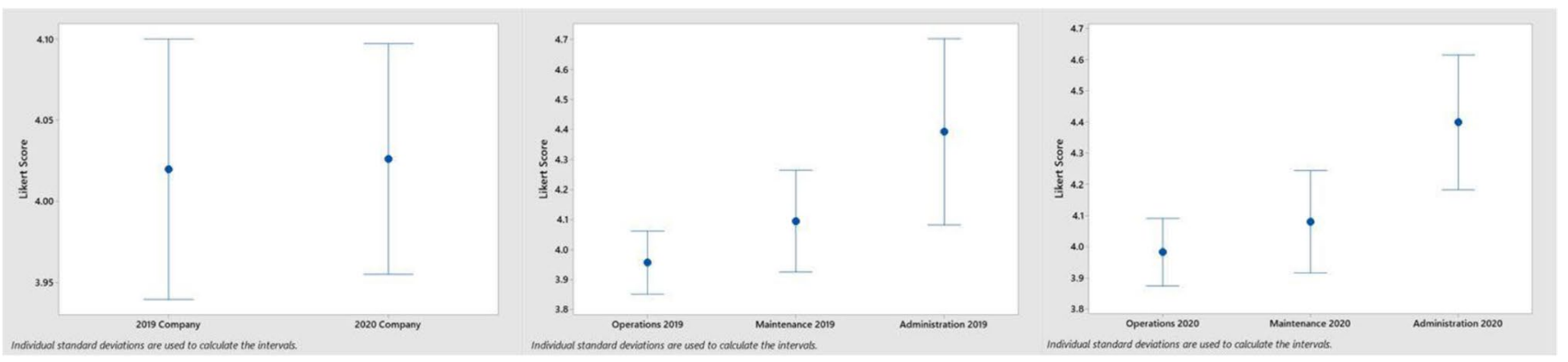

Fig. 1 Comparison of Means Scores from 2019 to 2020 for Company, Operations, and Maintenance

Table 6 Pre vs. post training assessment scores

\begin{tabular}{|c|c|c|c|c|c|c|c|}
\hline & Pre & & & Post & & & \\
\hline Question/Variable & Mean & SD & Median & Mean & SD & Median & $P$-Value \\
\hline 1. Lead by example & 4.6 & 0.85 & 5 & 4.9 & 0.30 & 5 & $<0.01$ \\
\hline 2. Engage my team members in safety & 4.5 & 0.97 & 5 & 4.9 & 0.37 & 5 & $<0.01$ \\
\hline 3. Actively listen when team members speak to me & 4.5 & 0.87 & 5 & 4.9 & 0.35 & 5 & $<0.01$ \\
\hline 4. Practice 3-way communication & 3.8 & 1.07 & 4 & 4.7 & 0.67 & 5 & $<0.01$ \\
\hline 5. Develop my team members through teaching, coaching, and providing feedback & 4.3 & 0.88 & 5 & 4.8 & 0.51 & 5 & $<0.01$ \\
\hline 6. Recognize team members for a job well done & 4.4 & 0.98 & 5 & 4.9 & 0.24 & 5 & $<0.01$ \\
\hline 7. Establish safety as a core value of my team & 4.5 & 0.77 & 5 & 5.0 & 0.24 & 5 & $<0.01$ \\
\hline 8. Maintain a positive attitude about safety & 4.7 & 0.65 & 5 & 4.9 & 0.30 & 5 & $<0.01$ \\
\hline 9. Set high safety expectations for team members & 4.5 & 0.69 & 5 & 4.9 & 0.35 & 5 & $<0.01$ \\
\hline 10. Follow safe work procedures and practices & 4.7 & 0.62 & 5 & 5.0 & 0.27 & 5 & $<0.01$ \\
\hline 11. Communicate with my team that everyone owns safety & 4.5 & 0.79 & 5 & 4.9 & 0.38 & 5 & $<0.01$ \\
\hline 12. Engage team members in daily safety meetings & 4.0 & 1.02 & 4 & 4.7 & 0.63 & 5 & $<0.01$ \\
\hline 13. Request input from team members about safety & 4.3 & 0.82 & 4 & 4.9 & 0.40 & 5 & $<0.01$ \\
\hline $\begin{array}{l}\text { 14. Encourage team members to report safety issues such as hazards, safety concerns, } \\
\text { near misses }\end{array}$ & 4.6 & 0.69 & 5 & 4.9 & 0.30 & 5 & $<0.01$ \\
\hline 15. Treat team members with respect when communicating with them & 4.7 & 0.64 & 5 & 4.9 & 0.38 & 5 & $<0.01$ \\
\hline 16. Actively listen to team members when they speak to me & 4.6 & 0.72 & 5 & 4.9 & 0.39 & 5 & $<0.01$ \\
\hline $\begin{array}{l}\text { 17. Practice } 3 \text {-way communication with team members to ensure my directions are } \\
\text { understood }\end{array}$ & 3.9 & 0.93 & 4 & 4.8 & 0.60 & 5 & $<0.01$ \\
\hline 18. Teach and coach team members in a respectful manner & 4.6 & 0.65 & 5 & 4.9 & 0.37 & 5 & $<0.01$ \\
\hline 19. Focus on the problem rather than judging the person when I give feedback & 4.3 & 0.73 & 4 & 4.8 & 0.58 & 5 & $<0.01$ \\
\hline 20. Make sure team members know how to do a task before they actually do it & 4.4 & 0.81 & 5 & 4.9 & 0.42 & 5 & $<0.01$ \\
\hline $\begin{array}{l}\text { 21. Say "good job" or "thank you" to team members who go above and beyond to create } \\
\text { a safe jobsite }\end{array}$ & 4.6 & 0.78 & 5 & 4.9 & 0.30 & 5 & $<0.01$ \\
\hline 22. Use positive recognition of team members to encourage jobsite safety & 4.5 & 0.72 & 5 & 4.9 & 0.36 & 5 & $<0.01$ \\
\hline $\begin{array}{l}\text { 23. Encourage safe work practices by praising team members who do more than the } \\
\text { minimum for safety }\end{array}$ & 4.5 & 0.72 & 5 & 4.9 & 0.41 & 5 & $<0.01$ \\
\hline
\end{tabular}

\section{Discussion}

The purpose of this study was to investigate and evaluate safety climate at a Montana metal mining company and assist the company with an intervention to improve its safety climate. The population characteristics of those surveyed were similar to national data reported by the
U.S. Bureau of Labor Statistics [4]. The BLS reported nearly $90 \%$ of US miners identified as white males [4]. The demographics section of the survey found $96 \%$ of the population at this mine identified as being male and 92.8\% identified as white. The BLS reported the combined industry sectors (mining, quarrying, and oil and gas extraction) had a population distribution of $87.3 \%$ white and $86.2 \%$ male [4]. Researchers were very successful in 
data collection; both 2019 and 2020 safety climate surveys achieved a response rate greater than $95 \%$. This investigation was able to achieve the three study aims: (1) Measure and evaluate potential differences in safety climate scores between the major divisions of the company; (2) Measure and evaluate middle and upper-management worker's understanding of FSL skills pre and posttraining; and, (3) Measure and evaluate safety climate scores comparing pre to postintervention.

Investigators rejected null hypothesis (1) and determined that statistically significant differences in mean safety climate scores existed between the three major divisions. Statistically significant differences were found when comparing the overall mean scores of all three divisions in both $2019(p$-value $=0.041)$ and $2020(p$-value $=0.041)$. Statistically significant differences in specific safety climate scores between operations maintenance and administration were found in many areas. These results were consistent with prior research that found group-level variation in safety climate within a single organization [36]. On most items, operations had the lowest mean score and administration had the highest mean scores. Administration had higher mean scores than operations and maintenance on 18 of 19 items in 2019 and 19 of 19 statements in 2020. These differences might be partially explained by the fact that operations and maintenance workers face significantly more hazardous working conditions than administrative personnel.

Some of the most common hazards in mining include rock fall, mobile equipment accidents, explosions, falls from height, and crystalline silica exposure [1]. Company administrative personnel routinely work at a desk or meeting room for the majority of their shift. They generally face fewer hazards and risks compared to maintenance and operations workers. Another research team concluded that higher levels of hazards in mining are a predictor for poor levels of safety and low safety climate [37]. We believe that this may partly explain the differences in scores seen our study between administration compared to the other two divisions that face more daily hazards in the course of their usual work.

A research team investigated a nuclear facility where they found administrative personnel's mean safety climate score was $10 \%$ higher than workforce/craft workers [38]. Results found in this study were similar, with administration having a mean score $10.2 \%$ higher than operations and $7.1 \%$ higher than maintenance in 2020 . When a worker from either group is asked to increase speed of work, it will likely lead to quicker fatigue and therefore increase the risk of making a mistake [39]. These factors elevate the likelihood the employee could suffer an injury or damage equipment [40]. Administration personnel do not face the same level of risk as operations and maintenance personnel when they are asked to increase work speed.
Operations and maintenance workers face similar hazards on a consistent basis while working at the mine site. This could explain why operations and maintenance scores for both 2019 and 2020 were more similar than administrations' scores. Though these divisions were more comparable than administration, maintenance had a significantly higher median score than operations in 2019 ( $p$-value $=0.07$ ). Maintenance also scored higher on 16 of 19 items in 2019 and 2020. A possible explanation for the differences found between operations and maintenance is the amount of interaction between employees and their supervisors/foremen within each group. Maintenance workers tend to have more face-to-face interaction with direct supervisors/foreman than operations workers due to simple geographical work area differences. The work area for maintenance workers is more of a team environment with each crew being limited to three or fewer buildings. Operations personnel on the other hand are located throughout the entire mine site, for example a worker may be isolated to a haul truck for their entire shift moving ore from excavation locations to dump locations. These types of jobs limit communication between workers and supervisor/foremen to primarily mobile radio use. Looking at some of the safety climate items with larger differences in mean scores between operations and maintenance, it is noted that most are linked to communication with supervisors/foreman. Communication is the key to an effective safety climate [40]. Being limited to mobile radio communication as the primary source of interaction between foremen/supervisors and workers could negatively impact the relationship potential. Another investigator found that face-to-face communication most effective in building interpersonal relationships between employees and managers when comparing it to computer-mediated communication [41].

Variability exists in the work schedules of the company's three major divisions. Operations workers work 12-h shifts, with one of four crews working onsite at all times, and all crews rotating between day and night shift. Maintenance workers are scheduled from 7 A.M. to 3:30 P.M. Monday through Friday, and they are on-call at all times in the event a pivotal piece of equipment breaks down. Administration workers generally work 7 A.M. to 3:30 P.M. A research team found that night shift workers perceived a higher level of injury risk compared to day shift workers [42]. Half of operations worker's shifts are night shifts, which may have negatively affected their safety climate scores.

Investigators rejected the null hypothesis (2) and found statistically significant differences when comparing pre vs. posttraining FSL assessment scores. All 23 items from the survey had statistically significant improvements. The authors believe that that the positive increase in scores represents a level of effectiveness of the training. Research have found similar evidence that the FSL training can, at least 
in the short-term, improve FSL assessment scores in construction frontline leaders [32]. Their results were similar to the ones found in this study. They also acknowledged that further research is necessary to determine if these results lead to long-term improvements [32]. The company plans on continuing to focus on safety training in the future as the major strategy to improve their safety climate.

Recently, a research team that investigated numerous mining operations found that improving training, communication, and follow-up after training should be considered highest priority rather than the volume of training for improving safety climate [43]. At the mine, work teams continued to meet daily at the beginning of each shift and practiced FSL skills however, when COVID 19 restrictions were implemented group leaders experienced difficulty maintaining effective safety group and individual practices. The short video training messages produced by CPWR for the five leadership skills were evaluated by senior management. They did not feel that the content within the messaging would be effective and opted to not use them. Formal followup training did occur with monthly messaging to reinforce FSL skills and practices. The next MSHA mandated annual refresher training in 2020 included additional reinforcement of FSL practices in combination with the second safety climate survey. At the sessions employees in small groups received eight hours of training that included one full hour of FSL refresher training by the research team leader via video.

Researchers also found, in general that the mining industry often lacked "soft skills" training such as sustaining communication and leadership [43]. The FSL training targets these "soft skills" and researchers in this study found a high level of engagement in the miners who took the class. This high level of engagement was reflected by the pre vs. post training assessment scores. Attendees provided good interaction and understood the importance of soft skills in effective safety related communication. There was discussion about the barriers and ideas to overcome them. For example, just making sure that employees were paying attention and understood the safe work practice could be confirmed by practicing three-way communication. A research team performed a comprehensive literature review on training effectiveness and concluded that further research on high quality training effectiveness was needed [44]. This study demonstrates that FSL training has the potential to increase miners with management responsibilities' knowledge of safety leadership skills. We recommend that the company continue to support the FSL practices and believe that over time safety climate scores will improve.

Posttraining scores suggested that these managers enhanced their safety leadership skills and that they could use them to improve communication with the employees they oversee. Prior research has found frontline leaders who display a "caring" dimension are particularly effective in safety leadership [45]. The FSL training stresses the importance of actively listening, engaging, empowering, and communicating with all members of their workforce. When these skills are put to use, it convey a message to workers they are valued members of a team. The authors believe that if managers utilized the skills learned from FSL training they could become better safety leaders and therefore improve the company's safety climate. At the company, safety training conveys the message that everyone is a safety leader. Given that the company had a high level of safety climate prior to the onset of the study, it will be a challenge to move the climate scores to significantly higher levels. Improving safety climate takes time, determination, stamina, leadership support, commitment, reinforcement, and long-term focus [46]. The company has a stellar record with more than ten years without a lost time injury and has worked hard to build a positive safety climate. Senior management and front-line supervisors felt that the FSL training was right for their company for many reasons.

Safety is a core value at the company. Management buy-in and support for safety have been identified as best-in-class features of good companies [47]. Commitment to safety is embedded in the organization and its structure from workers and front-line supervisors to top management, they have a strong safety climate and only wish to get better. Organizations that demonstrate this kind of commitment and seize the opportunity to reinforce safety at every turn are poised for continuous improvement [47]. The FSL was and is a good fit approach for improving safety climate for this organization. Given the level of commitment, positive FSL implementation, and reinforcement, authors believe that over time safety climate measures will improve as seen by other companies who demonstrated similar strategies [33, 48].

The FSL program has been found to be effective in construction for improving safety leadership skills [48]. Key to the success of FSL is the effective training, not only because of the knowledge and skills learned but, because the program increases motivation and self-efficacy of those trained [48]. The FSL program had significant promise to impact safety in construction and was adopted by the Occupational Safety and Health Administration (OSHA) and designed into a 30-h stand-alone course. As of 2019, more than 60,000 leaders have been trained in the FSL [28]. This study is the first to our knowledge of the FSL being used in mining. The FSL program was designed to be adapted to most industries and was a good fit for mining and the company studied [29].

Investigators failed to reject the null hypothesis (3) that no statistically significant changes would occur between the pre and post-training safety climate measurements. Investigators did see an increase from 76.35 pre-training to 76.49 posttraining out of a possible 95 . The mean scores were 4.02 for 2019 and 4.03 for 2020. This increase was not found to be statistically significant ( $p$-value $=0.616$ ). Investigators 
also observed an increase in positive responses with $74.8 \%$ of total responses being positive in 2019 compared to $75.8 \%$ in 2020, a negligible increase of $1 \%$.

Researchers in Ghana used surveys to assess the maturity of safety climate in a large gold mine operation with 9,767 employees located at four sites. Investigators administered 1,040 surveys across the four sites and received 828 back for an $80 \%$ response rate. Researchers found an overall climate score of 3.42 from a possible 5.0 with a $68 \%$ positive response. Significant differences were found between various mine locations [26]. They found a higher safety climate maturity was correlated with lower incidence rate among the four mines [26]. The authors believe the high baseline measurement (4.02) correlates well with the fact the mine surveyed in this study had gone over 11 years without a lost time injury as of February 2021. This extraordinary achievement speaks to the high level of safety management in place at the mine. Mine operators in this study stated that they go above and beyond annual refresher training required by the MSHA. This includes mandatory daily toolbox talks, monthly FSL reminders, and various annual trainings depending on the employee's job and responsibilities, such as first aid, trench safety, fall protection, and lockout tagout. Research supports the assertion that all mine operators should implement safety training beyond what is required by law [43]. The high initial state of the company's safety climate makes it more difficult to increase the company's safety climate.

The FSL training assessment demonstrated significant improvements on all 23 items when comparing the pre vs. posttraining results, this improvement did not translate to improved posttraining safety climate scores over the period of time studied. Investigators replicated and validated the Ebbinghaus forgetting curve research that claimed people often forget $90 \%$ of what they learned within 3-6 days unless learning is reinforced with multiple repetitions [49]. This research aligns with claims made by other research teams who found that reminding employees of training concepts and post-training communication may be the key to improving employees' safety knowledge [43]. The FSL training has been found to be effective on follow-up with supervisors 4 weeks post intervention [48]. Long-term studies using the FSL have not been published thus far but are expected in the future.

A limited follow-up plan was used in conjunction with the training intervention to consistently reinforce supervisors/managers of FSL training concepts and practices after training concluded. By consistently reminding employees of the skills they learned in the FSL training, they may be more likely to utilize the skills on their jobsites. Experts have recommended to go beyond the annual refresher to reinforce training and safe work practices [43]. These authors recommend the company continue their strategies and believe long-term reinforcement of FSL will lead to a greater adoption of safety leadership skills by both front-line supervisors and workers. Over time, investigators expect measurable improvement in safety climate scores at the company as seen in other companies with committed, supportive, positive leadership for safety [33].

Another possible factor that may have negatively affected post-training safety climate scores was the occurrence of COVID-19 pandemic during this study. Three-months before the posttraining safety climate assessment the World Health Organization declared COVID-19 a pandemic [50]. The Center for Disease Control and Prevention stated that COVID-19 pandemic can cause stress, fear, and anxiety for people [51]. They also reported that social distancing protocols utilized by the mine operators to reduce the spread of COVID-19 can make people feel isolated and further increase stress and anxiety [51]. Therefore, COVID-19 is a variable that could have biased scores toward the null. In light of the COVID-19 pandemic occurring prior to and throughout the post intervention assessment, the small but insignificant increase in safety climate scores is remarkable.

\section{Limitations}

This study has a number of limitations. The safety climate surveys were completed by individuals and may be subject to response bias. Self-report surveys are also subject to recall bias. Individuals may not have accurately recalled the circumstances for which they formed their opinions. The company experienced changes in middle to upper management positions between 2019 and 2020 during the study period. This could also have led to bias in the results of 2020 either toward or away from the null depending on how employees perceived the new managers views on safety. The newly appointed management personnel also did not receive Foundations for Safety Leadership training and therefore were not taught the skills to make potential improvements in the company's safety climate. The high level of safety climate and safe work practices in place at the mine bias the results toward the null. The company may not represent the average metal mine in Montana or elsewhere.

\section{Conclusions}

In this study we found statistically significant differences in safety climate between the company's three major divisions in both 2019 and 2020 . We also found statistically significant differences in the FSL pre vs. posttraining assessment scores indicating the training was effective. Despite the positive evaluation findings, we did not see a statistically significant increase in the overall company 
mean safety climate scores when comparing 2019 to 2020 . The company has all the right pieces in place to succeed at raising their safety climate and culture over time.

Leadership is foundational to improving organizational climate [33 40 52]. The company practices a transformational leadership style, which has been found to have a strong relationship to safety behaviors and reduced losses $[28,53]$. Leadership by example, with competency and consistency builds positive organizational climate and culture [40]. A number of leadership practices have been recommended for improving safety climate by experts such as practicing consideration for all employee's contributions, wellbeing, and status within the company, providing clarity of leadership structure, responsibilities, and expectations throughout the organization, representation of personnel at all levels within the organization, reconciliation of conflicting demands within organizational operations, tolerance of uncertainty, persuasiveness, tolerance for freedom in opinions of followers and differences in perspective, role retention for leadership, predictive accuracy, acumen, and planning, production emphasis, integration and alignment of company policy and roles, transparency, and influence of subordinates on superiors [33].

Other experts recommended enhanced omni-directional communication that aligns the organization to the vision, mission and values of the company and reinforces safe work practices [40]. Alignment of production and safety goals are key factors that demonstrate company commitment to safe work practices and raise climate and culture [40]. Accountability for all employees in relation to company safety standards, rules and practices, and to lead by example is important for enhancing safety climate [40]. Creating opportunities for meaningful employee involvement and empowerment builds company culture and safety climate [40]. Effective training and education that includes adequate intensity, frequency, and duration to bring about adoption of safe work practices as normal and usual for all duties and tasks. Effective training supports self-efficacy and motivation for compliance [48]. Building mutual trust between individuals and groups within the organization is also important for creating and enhancing positive organizational culture and safety climate [45].

Measuring and monitoring leading indicators for safe work is also a pathway to prevention [54]. If the company continues to be proactive about identifying gaps in safe work practices, responds positively, and reinforces correction in procedures, tools, and/or conditions, improvement in lagging indicators will follow. Companies that maintain robust reporting systems for frontline safety needs, performance, injury, illness, and near misses may also expect to improve safety climate [47]. The company uses multiple measures for leading indicators from frequent audits, regular employee-management communication and exchanges, and annual company climate and safety climate surveys.

Strong safety leadership is the best approach to improving safety climate within an organization [33]. The next phase of this study includes continued discussion with company leaders to identify, develop, and implement additional strategies to further improve safety climate followed by future reevaluations to assess changes in safety climate scores for the company as a whole and by division. In the meantime, practices to improve the company's safety climate continue including follow-up reinforcement of the FSL training and frequent communication with supervisors and employees to remind them of key safety leadership concepts and practices.

Acknowledgements This study was supported in part by the National Institute for Occupational Safety and Health Training Project Grant (grant no. T03OH008630). The contents of this publication are solely the responsibility of the authors and do not represent official views of the CDC or NIOSH.

Author Contributions Ty Murphy, lead author, was a graduate student earning an MS degree. Dr. Gilkey was Chair of the graduate committee and oversaw the study from conception to completion. Mr. Hadi Aldossari was an undergraduate student working under Dr. Gilkey and participated in in all phases of the initial baseline measurement process, data collection, coding, data entry, analysis, and FSL intervention. Dr. Autenrieth provide statistical support. Professor Birkenbuel was a graduate committee member and contributed to all phases of the study. Professor Rosenthal was a graduate committee member and participated in all phases of the study. Mr. McGivern is an adjunct professor in the department and represented the community partner and participated in all phases of the project.

\section{Declarations}

Conflicts of Interest The authors declare no conflict of interest.

\section{References}

1. Donoghue AM (2004) Occupational health hazards in mining: an overview. Occup Med 54(5):283-289. https://doi.org/10.1093/ occmed/kqh072

2. Kowalski-Trakofler K, Barrett E (2003) The concept of degraded images applied to hazard recognition training in mining for reduction of lost-time injuries. J Safety Res 34(5):515-525. https://doi. org/10.1016/j.jsr.2003.05.004

3. Morbidly and Mortality Weekly (MMWR) (1999) Achievements in Public Health, 1900-1999: Improvements in Workplace Safety-United States, 1900-1999, MMWR, 48(22), 461-469. Retrieved from https://www.cdc.gov/mmwr/preview/mmwrhtml/ mm4822a1.htm. Accessed 8 Aug 2021

4. Bureau of Labor and Statistics (BLS) (2018) Mining at a glance (except oil and gas): NAICS 212. https://www.bls.gov/iag/tgs/ iag212.htm. Accessed 8 Aug 2021

5. NIOSH (n.d.) Number and rate of nonfatal lost-time injuries per sector, 2016 - 2019 https://wwwn.cdc.gov/niosh-mining/MMWC/ Injuries/NumberAndRateBySector. Accessed 8 Aug 2021 
6. Saleh J, Cummings A (2011) Safety in the mining industry and unfinished legacy of mining accidents: safety levers and defensein-depth for addressing mining hazards. Saf Sci 49(6):764-777. https://doi.org/10.1016/j.ssci.2011.02.017

7. Marshall, R (1981) Mine safety health administration. https:// www.dol.gov/general/aboutdol/history/carter-msha\#: : text= MSHA $\% 20$ was $\% 20$ created $\% 20$ in $\% 20$ the,to $\% 20$ the $\% 20$ Bureau $\%$ 20of\%20Mines. Accessed 8 Aug 2021

8. Waehrer G, Miller T (2009) Does safety training reduce work injury in the United States? The Ergonomics Open Journal 2:2639. https://doi.org/10.2174/1875934300902010026

9. Bonsu J, van Dyk W, Franzidis J-P, Petersen F, Isafiade A (2017) A systemic study of mining accident causality: an analysis of 91 mining accidents from a platinum mine in South Africa. J South Afr Inst Min Metal 117(1):59-66. https://doi.org/10.17159/24119717/2017/v117n1a9

10. Filigenzi M, Orr T, Ruff T (2010) Virtual Reality for Mine Safety Training. Appl Occup Environ Hyg 15(6):465-469. https://doi. org/10.1080/104732200301232

11. van Wyk E, Villiers R (2009) Virtual reality training applications for the mining industry. In: Proceedings of the 6th international conference on computer graphics, virtual reality, visualisation and interaction in Africa, pp 53-63. https://doi.org/10.1145/1503454. 1503465

12. Camm T, Girard-Dwyer J (2005) Economic consequences of mining injuries. National Institute for Occupational Safety and Health, Spokane Research Laboratory. https://www.cdc.gov/NIOSH/Mining/UserFiles/works/pdfs/ecomi.pdf. Accessed 8 Aug 2021

13. Heberger JR (2018) Demonstrating the financial impact of mining injuries with the "Safety Pays in Mining" web application. Min Eng 70(12):37-43. https://doi.org/10.19150/me.8643

14. Zohar D (2010) Thirty years of safety climate research: reflections and future directions. Accid Anal Prev 42(5):1517-1522. https:// doi.org/10.1016/j.aap.2009.12.019

15. Zohar D (1980) Safety climate in industrial organizations: theoretical and applied implications. J Appl Psychol 65:96-102. https:// doi.org/10.1037/0021-9010.65.1.96

16. Gilkey D, Lopez del Puerto C, Keefe T, Bigelow P, Herron R, Rosecrance J, Chen P (2012) Safety culture in residential construction: managers vs workers. J Constr Eng Manag 138(10441052):1045. https://doi.org/10.1061/(ASCE)CO.1943-7862.00005 19

17. Huang Y, Lee J, Chen Z, Perry M, Cheung J (2017) An itemresponse theory approach to safety climate measurement: the Liberty Mutual Safety Climate Short Scales. Accid Anal Prev 103:96-104. https://doi.org/10.1016/j.aap.2017.03.015

18. Froko IUF, Maxwell A, Kingsley N (2015) The impact of safety climate on safety performance in a gold mining company in Ghana. International Journal of Management Excellence 5(1):556-566

19. Pandit B, Albert A, Patil Y, Al-Bayati A (2019) Impact of safety climate on hazard recognition and safety risk perception. Saf Sci 113:44-53. https://doi.org/10.1016/j.ssci.2018.11.020

20. Sparer E, Catalano P, Herrick R, Dennerlein J (2016) Improving safety climate through a communication and recognition program for construction: a mixed methods study. Scand J Work Environ Health 42(4):329-337. https://doi.org/10.5271/sjweh.3569

21. Huang YH, Lee J, McFadden AC, Murphy LA, Robertson MM, Cheung JH, Zohar D (2016) Beyond safety outcomes: an investigation of the impact of safety climate on job satisfaction, employee engagement and turnover using social exchange theory as the theoretical framework. Appl Ergon 55:248-257

22. Balogun AO, Andel SA, Smith TD (2020) "Digging Deeper" into the relationship between safety climate and turnover intention among stone, sand and gravel mine workers: job satisfaction as a mediator. Int J Environ Res Public Health 17(6):1925. https://doi. org/10.3390/ijerph17061925

23. Shaw D (2010) Turnover rates and organizational performance: review, critique, and research agenda. Sage Publishing 1(3):187213. https://doi.org/10.1177/2041386610382152

24. Masia U, Pienarr J (2011) Unravelling safety compliance in the mining industry: examining the role of work stress, job insecurity, satisfaction and commitment as antecedents. SA J Ind Psychol 37(1):1-10. http://www.scielo.org.za/scielo.php?script=sci_artte xt\&pid=S2071-07632011000100018. Accessed 8 Aug 2021

25. Firoozi C, Beheshti M, Poursadeghiyan M (2015) Effect of health, safety, and environment management system training on safety climate in a mine in Yazd Province, Iran. Journal of Occupational Health and Epidemiology 4(4):198-204. http://johe.rums.ac.ir/ article-1-153-en.html. Accessed 8 Aug 2021

26. Stemn E, Bofinger C, Cliff D, Hassall M (2019) Examining the relationship between safety culture maturity and safety performance of the mining industry. Saf Sci 113:345-355. https://doi. org/10.1016/j.ssci.2018.12.008

27. Ma Q, Yuan J (2009) Exploratory study on safety climate in Chinese manufacturing enterprises. Saf Sci 47(7):1043-1046. https:// doi.org/10.1016/j.ssci.2009.01.007

28. Goldenhar L, Schwatka N, Johnson S (2019) Leadership skills for strengthening jobsite safety climate. J Safety Res 70:263-271. https://doi.org/10.1016/j.jsr.2019.04.011

29. Center for Construction Research and Training (CPWR) (2021) Foundation for safety leadership (FSL). https://www.cpwr.com/ research/training-and-awareness-programs-from-research/found ations-for-safety-leadership/. Accessed 8 Aug 2021

30. Flin R (2007) Measuring safety culture in healthcare: a case for accurate diagnosis. Saf Sci 45(6):653-667. https://doi.org/10. 1016/j.ssci.2007.04.003

31. Kozlowski SW, Doherty ML (1989) Integration of climate and leadership: examination of a neglected issue. J Appl Psychol 74(4):546-553. https://doi.org/10.1037/0021-9010.74.4.546

32. Schwatka N, Goldenhar L, Johnson S, Beldon M, Tessler J, Dennerlein J, Fullen M, Hao T (2019) A training intervention to improve frontline construction leaders' safety leadership practices and overall jobsite safety climate. J Safety Res 70:253-262. https://doi.org/10.1016/j.jsr.2019.04.010

33. Williams JH (2002) Improving safety leadership. Prof Saf 47(4):43-47. http://mtproxy.lib.umt.edu:3048/login?url=https:// www.proquest.com/docview/200407769? accountid=28080. Accessed 8 Aug 2021

34. Amponsah-Tawiah K, Ntow M, Mensah J (2015) Occupational Health and Safety Management and Turnover Intention in the Ghanaian Mining Sector. Saf Health Work 7(1):12-17. https:// doi.org/10.1016/j.shaw.2015.08.002

35. Liberty Mutual Insurance (2019) Liberty mutual safety climate short scale survey. Liberty Mutual Insurance, Boston, MA

36. Zohar D, Luria G (2005) A Multilevel Model of Safety Climate: Cross-Level Relationships Between Organization and GroupLevel Climates. J Appl Psychol 90(4):616-628. https://doi.org/ 10.1037/0021-9010.90.4.616

37. Jiskani I, Cai Q, Zhou W, Chang Z, Chalgri S, Manda E, Lu X (2020) Distinctive Model of Mine Safety for Sustainable Mining in Pakistan. Mining, Metallurgy \& Exploration 37:1023-1037. https://doi.org/10.1007/s42461-020-00207-8

38. Findley M, Smith S, Gorski J, O'neil M, (2006) Safety climate differences among job positions in a nuclear decommissioning and demolition industry: employees' self-reported safety attitudes and perceptions. Saf Sci 45(8):875-889. https://doi.org/10.1016/j.ssci. 2006.08.027 
39. MacDonald W (2003) The impact of job demands and workload on stress and fatigue. Aust Psychol 38(2):102-117. https://doi.org/ 10.1080/00050060310001707107

40. Putz-Anderson V, Bernard B, Bur SE, Cole LL, Fairfield-Estill C, Fine L, Grant K, Gjessing G, Jenkins L, Hurrell JJ, Nelson N, Pfirman D, Roberts R, Stetson D, Haring-Sweeney M, Tanaka S (1997) Musculoskeletal disorders and workplace factors: a critical review of epidemiologic evidence for work-related musculoskeletal disorders of the neck, upper extremity, and low back. https:// www.cdc.gov/niosh/docs/97-141/default.html. Accessed 8 Aug 2021

41. Gilkey D, Lopez del Puerto C (2018) There is culture and there is safety culture: lessons learned from construction. World Safety Journal 27(4):5-12. https://worldsafety.org/wp-content/uploads/ WSJ_VolXXVII_No4-2018.pdf. Accessed 8 Aug 2021

42. Ean L (2010) Face-to-face versus computer-mediated communication: exploring employees' preference of effective employee communication channel. International Journal for The Advancement of Science \& Arts 1(2):38-47. https://scholar.google.com/ scholar?hl=en\&q=Ean\%2C+L.C.+Face-to-face+Versus+Compu ter-mediated+Communicaton $\% 3 \mathrm{~A}+$ Exploring+Employee\%27s+ Preference + of + Effective + Employee + Communication + Chann el.+International+Journal+for+the+Advancement+of+Scien ce+and+Arts $\% 2 \mathrm{C}+2010 \% 2 \mathrm{C}+1+\% 282 \% 29 .+38 \% 2 \mathrm{D} \% 2 \mathrm{D} 47$. Accessed 8 Aug 2021

43. Huang Y, Chen J, Dearmond S, Cigularov K, Chen P (2007) Roles of safety climate and shift work on perceived injury risk: a multilevel analysis. Accid Anal Prev 39(6):1088-1096. https://doi.org/ 10.1016/j.aap.2007.02.006

44. Haas E, Hoebbel C, Yorio L (2020) U.S. Department of Health and Human Services, Centers for Disease Control and Prevention, National Institute for Occupational Safety and Health, DHHS (NIOSH) Publication No. 2020-120, RI 9704. https://doi.org/10. 26616/NIOSHPUB2020120

45. Robson L, Stephenson C, Schulte P, Amick B, Chan S, Bielecky A, Wang A, Heidotting T, Irvin E, Eggerth D, Peters R, Clarke J, Cullen K, Boldt L, Rotunda C, Grubb P (2010) A systematic review of the effectiveness of training \& education for the protection of workers. National Institute for Occupational Safety and
Health. Publication No. 2010-127. https://www.cdc.gov/niosh/ docs/2010-127/pdfs/2010-127.pdf. Accessed 8 Aug 2021

46. Wu C, Wang F, Zou P, Fang D (2016) How safety leadership works among owners, contractors and subcontractors in construction projects. Int J Project Manage 34(5):789-805. https://doi.org/ 10.1016/j.ijproman.2016.02.013

47. Stiles S, Ryan B, Golightly D (2018) Evaluating attitudes to safety leadership within rail construction projects. Saf Sci 110:134-144. https://doi.org/10.1016/j.ssci.2017.12.030

48. Mannan MS, Mentzer RA, Zhang J (2013) Framework for creating a Best-in-Class safety culture. J Loss Prev Process Ind 26(6):1423-1432. https://doi.org/10.1016/j.jlp.2013.09.007

49. Schwatka NV, Goldenhar LM, Johnson SK (2020) Change in frontline supervisors' safety leadership practices after participating in a leadership training program: does company size matter? J Safety Res 74:199-205. https://doi.org/10.1016/j.jsr.2020.06.012

50. Murre J, Dros J (2015) Replication and analysis of Ebbinghaus' forgetting curve. PLoS ONE 10(7). https://doi.org/10.1371/journ al.pone. 0120644

51. World Health Organization (2020) Archived: WHO Timeline COVID-19. https://www.who.int/news-room/detail/27-04-2020who-timeline---covid-19. Accessed 8 Aug 2021

52. Center for Disease Control and Prevention (CDC) (2020) Coping with Stress. https://www.cdc.gov/coronavirus/2019-ncov/dailylife-coping/managing-stress-anxiety.html. Accessed 8 Aug 2021

53. Jiang L, Probst TM (2016) Transformational and passive leadership as cross-level moderators of the relationships between safety knowledge, safety motivation, and safety participation. J Safety Res 57:27-32. https://doi.org/10.1016/j.jsr.2016.03.002

54. Sheehan C, Donohue R, Shea T, Cooper B, De Cieri H (2016) Leading and lagging indicators of occupational health and safety: the moderating role of safety leadership. Accid Anal Prev 92:130 138. https://doi.org/10.1016/j.aap.2016.03.018

Publisher's Note Springer Nature remains neutral with regard to jurisdictional claims in published maps and institutional affiliations. 